\title{
EFFECTIVENESS OF ANTI-SMOKING INTERVENTIONS TOWARDS COMMUNITY: A META-ANALYSIS STUDY
}

\author{
Egemen Ünal', Selma Metintaş² \\ ${ }^{1}$ Department of Public Health, Medical Faculty, Ankara Yildirim Beyazit University, Ankara, Turkey \\ ${ }^{2}$ Department of Public Health, Medical Faculty, Eskisehir Osmangazi University, Eskisehir, Turkey
}

\section{SUMMARY}

Objectives: Smoking is one of the biggest public health problems in the world. The World Health Organization (WHO) has declared the MPOWER package which provides a guide for tobacco control. The package includes six evidence based anti-smoking interventions. This meta-analysis study aims to assess the effectiveness of MPOWER - (M)onitor, (P)rotect, (O)ffer, (W)arn, (E)nforce, and (R)aise. In the study, "smoking prevalence rate, smoking cessation rate and number of cigarettes smoked daily" outputs were used in adult and adolescent age groups.

Methods: Literature search has been made with "smok", tobacco, cigarette" keywords from the databases of Medline, Web of Science, Scopus, and Cochrane-Library. Abstracts were assessed in detail according to the inclusion criteria by the research team. Quality of articles was evaluated with modified Jadad criteria. The follow-up periods of articles were determined in two groups named as short and long term periods. We used random effects model $(p \leq 0.05)$ and fixed effects model $(p>0.05)$ according to the heterogeneity test results.

Results: $\mathrm{P}$ and $\mathrm{O}$ interventions, which are evaluated with smoking cessation rate, increased the smoking cessation rate in adults by $39 \%$ in the longest follow-up period - RR: 1.39 (1.23-1.57). However, it was determined that the interventions were not effective on smoking cessation rate in adolescents - RR: $1.13(0.90-1.42$ ). Nicotine replacement therapy (NRT) was the most effective intervention for smoking cessation rate in adults. W interventions, which are evaluated with smoking prevalence rate, decreased the smoking prevalence rate in adults by $13 \%$ in the longest follow-up period - OR: $0.87(0.82-0.92)$. P, W and E interventions, which are evaluated with smoking prevalence rate, decreased the smoking prevalence rate in adolescents by $26 \%$ in the longest follow-up period - OR: $0.74(0.68-0.80)$.

Conclusions: MPOWER interventions affect smoking prevalence rate, smoking cessation rate and number of cigarettes smoked daily in different age groups. Well-controlled, well-planned and cost-effective anti-smoking interventions have great importance for public health protection.

Key words: meta-analysis, anti-smoking intervention, effectiveness

Address for correspondence: E. Ünal, Department of Public Health, Medical Faculty, Ankara Yildirim Beyazit University, Ankara, Turkey. E-mail: egemenunal28@hotmail.com

https://doi.org/10.21101/cejph.a6350

\section{INTRODUCTION}

Today, tobacco use is one of the biggest public health problems in the world (1). 1.2 billion people aged over fifteen are tobacco users in the world, whereas there are reported 16 million users in Turkey (2). Tobacco use is known as the primary risk factor for ischaemic heart diseases, cerebrovascular events, lower respiratory tract infections, chronic obstructive pulmonary disease, tuberculosis, and trachea-bronchus-lung cancers which constitute six of the eight major causes of death worldwide (3). According to WHO data, six million people die each year due to smoking in the world; more than $80 \%$ of them are affected by direct effects of tobacco use while the rest of them are affected by environmental tobacco smoke (1). It is estimated that the number of deaths from smoking will increase to 8 million in 2030 (4). It is also estimated that half of tobacco users will lose their lives due to smoking (5).

According to WHO data, the economic cost of tobacco use in the United States accounts for $6 \%$ (about $\$ 80$ billion) of the total healthcare expenditure. Tobacco use also causes indirect economic losses due to forest and household fires and absenteeism (6). The WHO General Assembly formulated the principles of tobacco control in the Framework Convention on Tobacco Control (FCTC) in 2003. The WHO published MPOWER package five years after the adoption of FCTC (7). MPOWER criteria include six evidence based anti-smoking interventions. These criteria are: Monitor $(\mathrm{M})$ : monitoring tobacco use, Protect $(\mathrm{P})$ : protecting people from the harm of passive smoking, Offer $(\mathrm{O})$ : offering help people to quit tobacco usage, Warn (W): warning people about the harms of tobacco, Enforce (E): prohibiting on tobacco advertising, promotion and sponsorship, Raise (R): raising the price and taxes of tobacco products (7). The main objective of this package is minimizing the tobacco smoke exposure on any children, adolescents and adults (8).

Turkey is the most successful country in adopting MPOWER policies according to WHO data from 2012 (9). Taking into account the enormous financial losses and loss of healthy life years caused by smoking, it is clear necessity that the improvement of anti-smoking intervention should continue (10). 
However, in spite of these implementations and achievements, high-level evidences are needed about which interventions are more effective and how and to what extent the anti-smoking interventions, which are planned and are implemented in accordance with the MPOWER criteria, are effective for several indicators of smoking (smoking frequency, smoking cessation rate, number of cigarettes smoked daily). In the light of this study results, policy makers will be able to find the chance to apply tobacco control programmes in a more systematic, efficient, comprehensive, cost-effective, and evidence-based manner.

The aim of the study is to evaluate the effectiveness of implementing policies related to five (POWER - Protect, Offer, Warn, Enforce, and Raise) of six MPOWER criteria, on "smoking prevalence rate, smoking cessation rate, number of cigarettes smoked daily" among adolescents and adults by meta-analysis method.

\section{MATERIALS AND METHODS}

\section{Study Type, Place and Duration}

This meta-analysis study was carried out at Eskişehir Osmangazi University Faculty of Medicine Department of Public Health in 2017.

The ethical approval was obtained from the Eskişehir Osmangazi University Faculty of Medicine Clinical Research Ethics Committee Presidency. Medical Specialization Project Proposal was presented to Eskişehir Osmangazi University Scientific Research Projects Commission. After the acceptance of project suggestion by the committee, the project has started. Within the scope of the project, two level meta-analysis courses were completed on the internet certificated program (www.statistics.com). A 1-year license of the comprehensive meta-analysis (CMA) program has been bought.

The MPOWER reports of WHO and literature were examined in detail in order to determine the interventions related to POWER sub-areas. Sub-areas of the POWER criteria are presented in Table 1.

\section{Detailed Literature Review}

Article search has been made with "smok*, tobacco and cigarette*" keywords from the databases of PubMed (MEDLINE), Web of Science, Scopus, and Cochrane Library. Subsequently the articles were transferred to the Thomson Reuters End-Note X7.4 reference management program. After the deletion of duplicated articles, the title, abstract and text reading processes of the articles were completed respectively by the research team.

\section{Search Strategy and Used Databases}

Keywords: smok*; tobacco; cigarette*; smok* or tobacco or cigarette*. Used databases: PubMed (MEDLINE); Web of Science; Scopus; and Cochrane Library.

In the context of manual article search, the source lists of the relevant articles, the previous issues of journals related to smoking, previously published reviews and meta-analyses were examined. Also in manual search, articles that meet the inclusion criteria were evaluated. In addition, authors were contacted for the articles in which the data are lacking necessary data. A total of 120,218 articles were reached with the search strategy determined in the four databases. After removing the duplicated articles, the remaining 65,915 articles were taken into consideration in the scope of the title and abstract reading.

After the title and abstract reading process, articles which will be included in full text reading were determined. The articles which were not related to the subject were classified in detail and excluded from the analysis.

The article search and elimination diagram for community trial studies and search flow for randomised control trials (RCT) were presented in Figures 1 and 2 (11).

\section{Search and Inclusion Criteria of Articles \\ - Original articles; \\ - Articles written in English; \\ - Articles in databases used in meta-analysis and systematic reviews; \\ - Studies of adolescent and adult age groups;}

Table 1. Sub-area interventions of POWER criteria

\begin{tabular}{|c|c|c|c|}
\hline $\begin{array}{l}\text { POWER } \\
\text { criteria }\end{array}$ & \multicolumn{2}{|l|}{ Sub-area interventions } & Main variable \\
\hline$P$ (Protect) & $\begin{array}{l}\text { - Studies towards families with children within the scope of prevention of } \\
\text { environmental cigarette smoke exposure } \\
\text { - Studies on prevention of smoking in hospitals } \\
\text { - Studies on prevention of smoking in workplaces } \\
\text { - Studies on prevention of smoking in schools }\end{array}$ & $\begin{array}{l}\text { (Group 1) } \\
\text { (Group 2) } \\
\text { (Group 3) } \\
\text { (Group 4) }\end{array}$ & $\begin{array}{l}\text { Smoking cessation rate } \\
\text { Smoking prevalence rate }\end{array}$ \\
\hline O (Offer) & $\begin{array}{l}\text { - Studies on smoking cessation lines towards society and telephone-based } \\
\text { smoking cessation studies } \\
\text { - Studies on smoking cessation training provided by health professionals } \\
\text { - Studies on nicotine replacement therapy }\end{array}$ & $\begin{array}{l}(\text { Group 5) } \\
\text { (Group 6) } \\
\text { (Group } 7)\end{array}$ & Smoking cessation rate \\
\hline W (Warn) & $\begin{array}{l}\text { - Studies on use of mandatory anti-smoking TV ads and media campaigns } \\
\text { - Studies on regulations for locating stimulant writing and pictures on } \\
\text { cigarette packs }\end{array}$ & $\begin{array}{l}\text { (Group 8) } \\
\text { (Group 9) }\end{array}$ & $\begin{array}{l}\text { Smoking prevalence rate } \\
\text { Number of cigarettes smoked daily }\end{array}$ \\
\hline E (Enforce) & $\begin{array}{l}\text { - Studies on prohibition of cigarette ads and sponsorships } \\
\text { - Studies on introduction of age limitation on the sale of cigarettes }\end{array}$ & $\begin{array}{l}\text { (Group 10) } \\
\text { (Group 11) }\end{array}$ & Smoking prevalence rate \\
\hline $\mathrm{R}$ (Raise) & - Studies on increasing price of cigarettes and taxes & (Group 12) & Number of cigarettes smoked daily \\
\hline
\end{tabular}




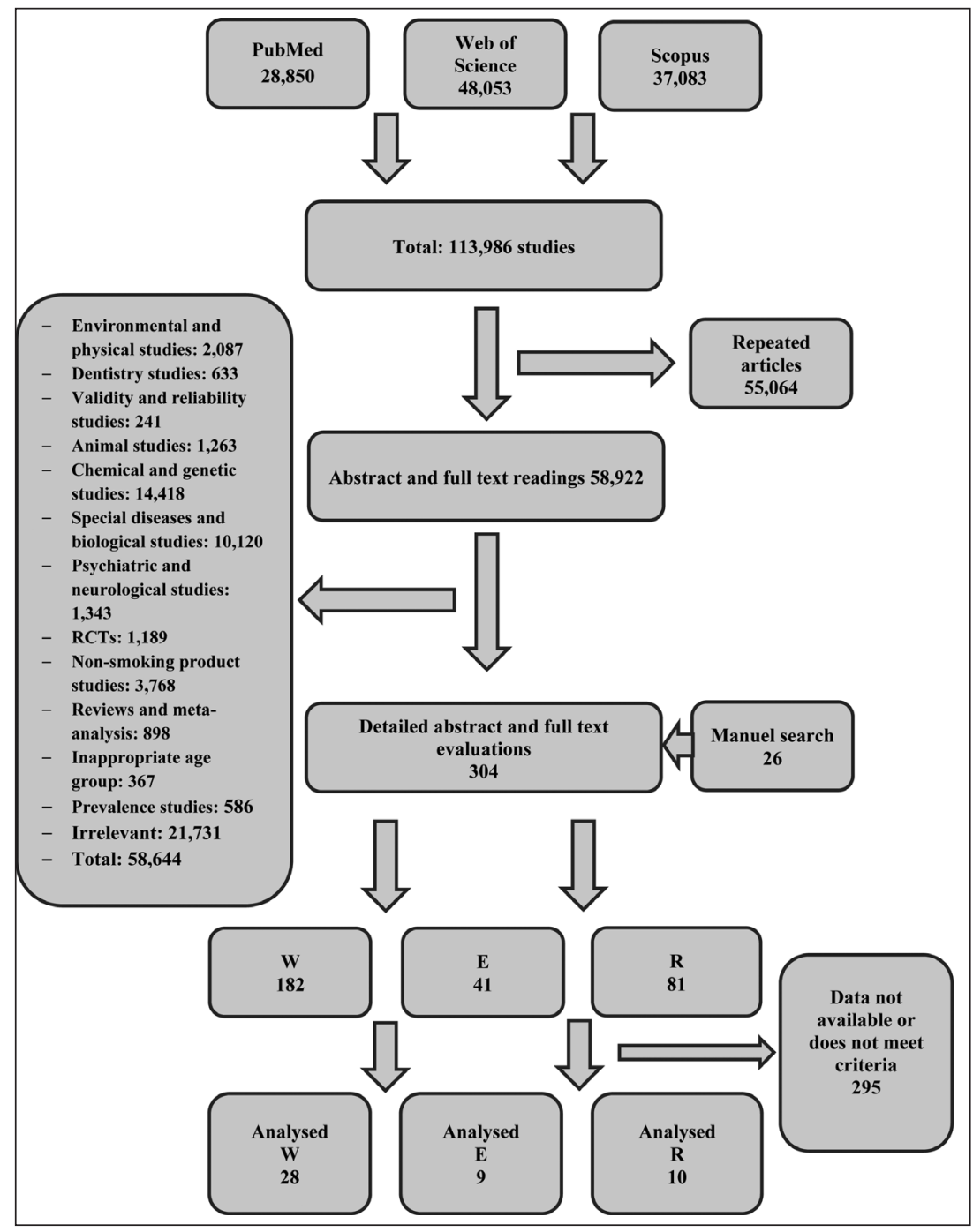

Fig. 1. Article search and elimination flow diagram for community trial studies.

- Articles for the last 13 years (2003-2016);

- Articles which have an intervention related to at least one sub-area of the POWER criteria;

- Community trial studies and intervention studies (RCT);

- Articles presented completely on several variables such as the total number of groups and the main outputs (smoking frequency, smoking cessation rate, number of cigarettes smoked daily).

\section{Reviewing, Coding and Evaluation Phase}

The abstract and full text readings of the articles were completed by two researchers/experts (project manager-researchers) in order to prevent publication bias. Evaluated articles were coded according to their descriptive characteristics (name, date of work, type of work, sample size of the study, implementation of the study, study time, the main output of the study, and intervention and control group data).

\section{Quality Assessment of Articles}

Quality assessments of articles were made according to Jadad criteria (12). Jadad criteria consist of 11 questions that allow quality assessment of RCTs in particular. Jadad criteria contain the following questions:

- Q1 Is the study described as randomized?

- Q2 Is the study defined as double blind?

- Q3 Is there a description in the study related to one that leave from the study and has been excluded from the study?

- Q4 Is the purpose of the study defined?

- Q5 Are the main outputs of the study clearly defined?

- Q6 Is there a clear definition of inclusion and exclusion criteria in the study?

- Q7 Is the sample size calculated in the study?

- Q8 Is there a clear definition related to intervention in the study?

- Q9 Is there at least one control group in the study?

- Q10 Are the side effects of the method used in the study defined?

- Q11 Has the statistical analysis been defined in the study?

Q1 and Q2 are counted as 2 points whereas the other questions are counted as 1 point. No score is presented for the criterion which is not provided (12). Total scores of articles vary between 0 and 13 .

In this study, qualities of articles were independently examined by two researchers. The scores of the articles given by both researchers were collected separately. The total quality score of 


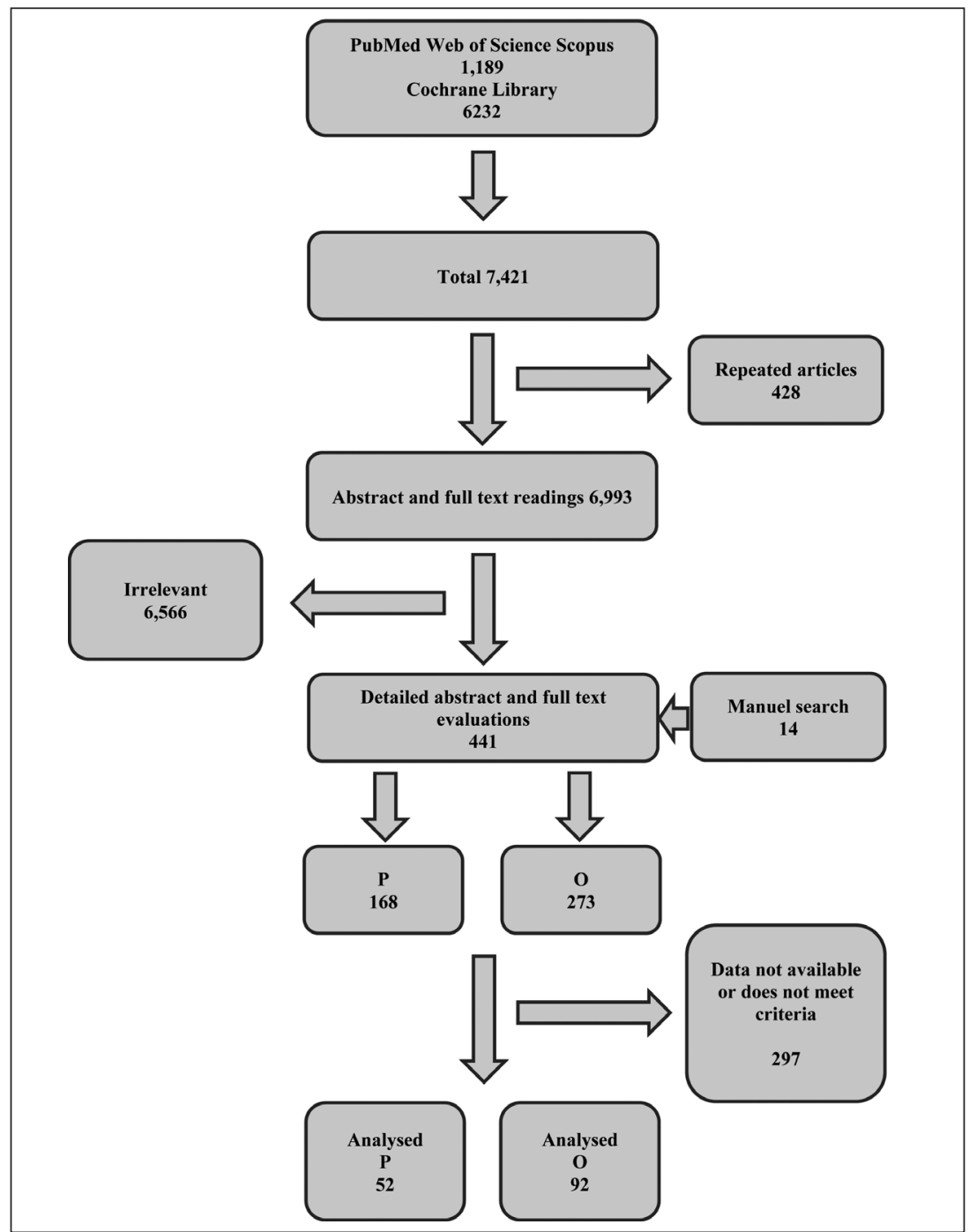

Fig. 2. Article search and elimination flow diagram for randomised control trials.

the articles were determined through calculating the arithmetic means of researchers' scores.

The RCT articles with a score of 6 and above were accepted as high quality. In the study, we modified Jadad criteria to evaluate quality of community trial studies. In the context of modification, the first two criteria (Q1, Q2) were excluded. In this case the community trial studies with a score of 4 and above were accepted as high quality.

\section{Main Outputs of the Study}

Smoking prevalence rate: The prevalence of smoking is evaluated as regular, intermittent and lifelong smoking in the articles. The prevalence of regular smoking is assessed as smoking at least one cigarette daily or smoking at least 4 days in the past week. Intermittent smoking prevalence is assessed as smoking at least 1 cigarette in the past 30 days or smoking at least one cigarette lifelong (13-16). The prevalence rates of regular and intermittent smoking were used in the analyses.

Smoking cessation rate: On determining the smoking cessation rate, "point smoking and continuous-prolonged smoking cessation rate" were used. Smoking cessation in the period of
7-30 days is named as "point smoking cessation rate" while smoking cessation in the period of 3 months or longer is named as "continuous-prolonged smoking cessation rate" at the end of the follow-up periods of the articles (17). For the analyses, we primarily used the data of "7 days point smoking cessation rate" and secondarily the data of "30 days point smoking cessation rate" in the evaluation of "point smoking cessation rate."

Number of cigarettes smoked daily: The number of cigarettes smoked daily was presented on daily and weekly basis in the articles. In our study, the data of number of cigarettes smoked daily was used. If the articles contain the number of cigarettes smoked per week, we used the article data after calculation of number of cigarettes smoked daily.

Follow-up period: A wide range of intervention follow-up periods were reported in the articles according to type of the sub-area interventions. The interventions of the articles with a follow-up period of less than six months were evaluated as "short-term" while six months and longer were evaluated as "long-term" (18). We analysed the interventions in the articles during the longest follow-up period.

In the articles, there were those who have left the study and who have been excluded from the study within the follow-up 
periods. Therefore, we preferred the data of studies which present their results with making "intention to treat (ITT) analysis". According to this analysis, those who have left the study and have been excluded from the study were evaluated in the control group which was not affected by the intervention (regular smoking).

Evaluation of smoking cessation: Cases of smoking cessation in the articles were determined using the own declaration of individuals or biochemical parameters (such as salivary and urine cotinine level, $\mathrm{CO}$ measurement, etc.). In this study, data of smoking cessation were primarily used by using biochemical parameters. In the studies which did not use biochemical parameters in determining smoking cessation, the data were used according to own declaration of individuals.

\section{Statistical Analyses}

In the current study, we analysed effectiveness of the POWER criteria on the main outputs in adults and adolescents. We also evaluated which intervention was more effective for the relevant output in the longest follow-up period.

At first, we evaluated the effectiveness of three sub-areas (group 1-3) from "P" criterion and three sub-areas (group 5-7) from "O" criterion on the smoking cessation rate in adults and adolescents.

Secondly, we analysed the effectiveness of one sub-area (group 4) from "P" criterion, two sub-areas (group 8-9) from W criterion and two sub-areas (group 10-11) from "E" criterion on the smoking prevalence rate in adults and adolescents.

Thirdly we evaluated the effectiveness of two sub-areas (group 8-9) from W criterion and one sub-area (group 12) from " $R$ " criterion on the number of cigarettes smoked daily in adults. In these three phases, we evaluated which sub-area is more effective for the relevant output.

The data of all articles that meet the inclusion criteria and decided to be included in the study were entered into CMA software. Heterogeneity status of the articles was evaluated. Under the title of random effects model $(p \leq 0.05)$ and fixed effects model $(p>0.05)$ to heterogeneity test, we calculated effect sizes, working weights, $95 \%$ confidence intervals and overall effect size of all studies. In the analysis of binary data, RR and OR values were grounded on the evaluating the overall effect size. Cohen's $\mathrm{d}$ coefficient was used for comparison of means and calculation of overall effect size and this coefficient was converted to the OR coefficient to compare the effectiveness between the areas. Statistically significant limit was accepted as $\mathrm{p} \leq 0.05$ on the evaluation of overall effect. Prisma checklist was used in the preparation of the study (11).

\section{RESULTS}

\section{Descriptive Results}

In the study, analysed articles belong to 12 sub-areas (group 1-12) of the POWER criteria (Table 1). Several studies were analysed that meet the inclusion criteria after evaluation of title, abstract, full-text readings, and quality assessment.

Thirteen studies conducted on adults in the sub-area of "studies towards families with children within the scope of prevention of environmental cigarette smoke exposure" belong to P criterion. Thirteen studies conducted on adults in the sub-area of "studies on prevention of smoking in hospitals" belong to P criterion. Six studies conducted on adults in the sub-area of "studies on prevention of smoking in workplaces" belong to P criterion. Twenty studies conducted on adolescents in the sub-area of "studies on prevention of smoking in schools" belong to P criterion.

Twenty-two studies conducted on adults and 6 studies conducted on adolescents in the sub-area of "studies on smoking cessation lines and telephone-based smoking cessation studies" belong to $\mathrm{O}$ criterion. Thirty studies conducted on adults and 9 studies conducted on adolescents in the sub-area of "studies on smoking cessation training served by health professionals" belong to $\mathrm{O}$ criterion. Twenty studies conducted on adults and 5 studies conducted on adolescents in the sub-area of "studies on nicotine replacement therapy" belong to $\mathrm{O}$ criterion.

Eleven studies conducted on adults and 6 studies conducted on adolescents in the sub-area of "studies on use of mandatory anti-smoking TV ads and media campaigns" belong to W criterion. Seven studies conducted on adults and 4 studies conducted on adolescents in the sub-area of "studies on regulations that locating stimulant writing and pictures on cigarette packs" belong to $\mathrm{W}$ criterion.

Four studies conducted on adolescents in the sub-area of "studies on prohibition of cigarette ads and sponsorships" belong to E criterion. Five studies conducted on adolescents in the sub-area of "studies on introduction of age limitation on the sale of cigarettes" belong to E criterion.

Ten studies conducted on adults in the sub-area of "studies on increasing the price of cigarettes and taxes" belong to R criterion.

\section{Meta-Analysis Results}

$\mathrm{P}$ (group 1-3) and $\mathrm{O}$ (group 5-7) interventions, which are evaluated with smoking cessation rate, increased the smoking cessation rate in adults by $39 \%$ in the longest follow-up period - RR: 1.39 (1.23-1.57). However, it was determined that the interventions were not effective for smoking cessation rate in adolescents - RR: 1.13 (0.90-1.42) (Fig. 3, 4). Nicotine replacement therapy (NRT) was the most effective intervention on smoking cessation rate in adults. The only effective intervention on smoking cessation rate in adolescents was "studies on prevention of smoking in schools". Meta-analysis diagram of the effectiveness of $\mathrm{P}$ and $\mathrm{O}$ interventions on the smoking cessation rate in adults and adolescents during the longest follow-up period is shown in Figures 3 and 4.

W (group 8-9) interventions, which are evaluated with smoking prevalence rate, decreased the smoking prevalence rate in adults by $13 \%$ in the longest follow-up period - OR: 0.87 (0.82-0.92). P (group 4), W (group 8-9) and E (group 10-11) interventions decreased the smoking prevalence rate in adolescents by $26 \%$ in the longest follow-up period - OR: $0.74(0.68-0.80)$ (Fig. 5, 6). While the most effective intervention on smoking prevalence rate in adults was "studies on use of mandatory anti-smoking TV ads and media campaigns (group 8)," the most effective intervention on smoking prevalence rate in adolescents was "studies on prohibition of cigarette ads and sponsorships" (group 10). Meta-analysis diagram of the effectiveness of criteria $\mathrm{P}, \mathrm{W}$ and $\mathrm{E}$ interventions on the smoking prevalence rate in adults 


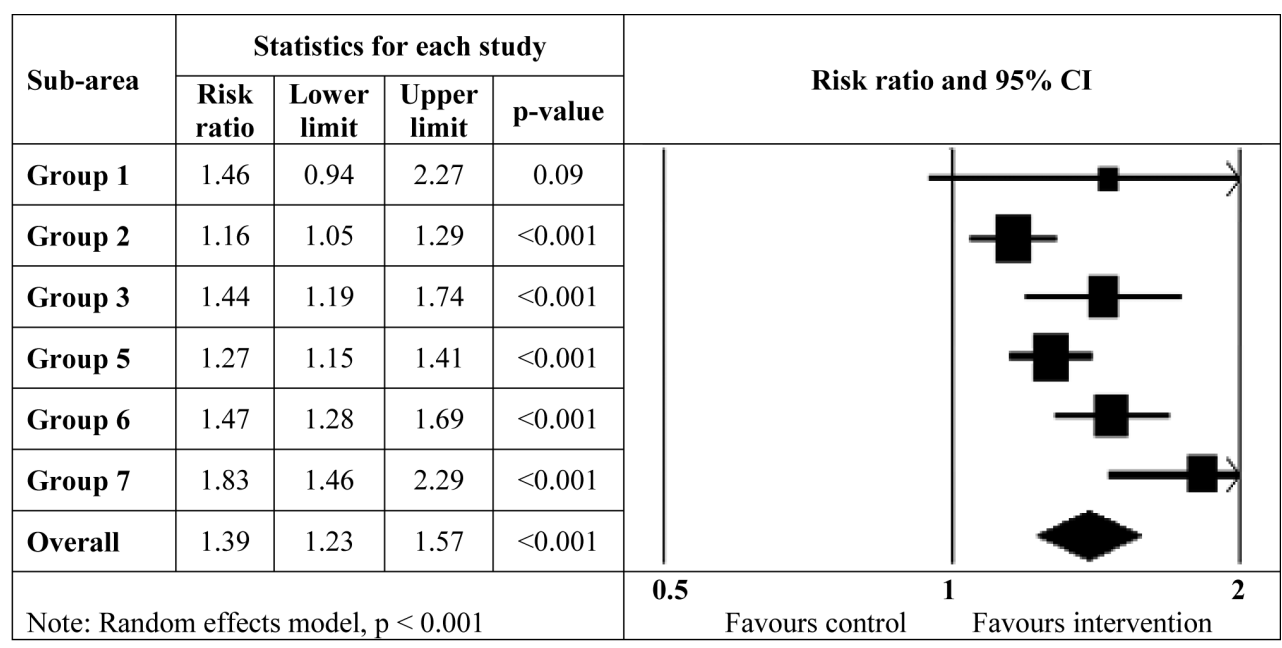

Fig. 3. Effectiveness of criteria $P$ (protect) and O (offer) on the smoking cessation rate in adults during the longest follow-up period.

\begin{tabular}{|c|c|c|c|c|c|c|}
\hline \multirow[b]{2}{*}{ Sub-area } & \multicolumn{4}{|c|}{ Statistics for each study } & \multirow{2}{*}{\multicolumn{2}{|c|}{ Risk ratio and $95 \% \mathrm{CI}$}} \\
\hline & $\begin{array}{l}\text { Risk } \\
\text { ratio }\end{array}$ & $\begin{array}{c}\text { Lower } \\
\text { limit }\end{array}$ & $\begin{array}{c}\text { Upper } \\
\text { limit }\end{array}$ & p-value & & \\
\hline Group 4 & 1.83 & 1.19 & 2.81 & 0.01 & & \\
\hline Group 5 & 1.07 & 0.85 & 1.34 & 0.56 & & \\
\hline Group 6 & 0.94 & 0.85 & 1.03 & 0.18 & & \\
\hline Group 7 & 1.16 & 0.81 & 1.67 & 0.42 & & \\
\hline Overall & 1.13 & 0.90 & 1.42 & 0.29 & & \\
\hline \multicolumn{7}{|c|}{ 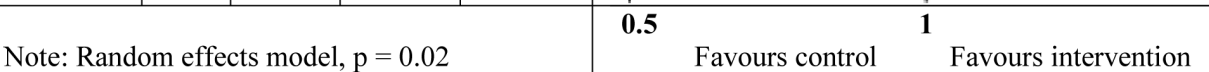 } \\
\hline
\end{tabular}

Fig. 4. Effectiveness of criteria P (protect) and O (offer) on the smoking cessation rate in adolescents during the longest followup period.

and adolescents during the longest follow-up period is shown in Figures 5 and 6.

W (group 8-9) and R (group 12) interventions, which are evaluated with the number of cigarettes smoked daily, were not effective for the number of cigarettes smoked daily in the longest follow-up period in adults - OR: $0.92(0.74-1.14)$. The only effective intervention on the number of cigarettes daily smoked in adults was "studies on regulations locating stimulant writing and pictures on cigarette packs" (group 9)". In our study, there were no articles which evaluated the effectiveness of interventions on number of cigarettes smoked daily in the adolescents. Metaanalysis diagram of the effectiveness of $\mathrm{W}$ and $\mathrm{R}$ interventions on the number of cigarettes smoked daily in adults during the longest follow-up period is shown in Figure 7.

\begin{tabular}{|c|c|c|c|c|c|}
\hline \multirow{2}{*}{ Sub-area } & \multicolumn{4}{|c|}{ Statistics for each study } & \multirow{2}{*}{ Odds ratio and $95 \% \mathrm{CI}$} \\
\hline & $\begin{array}{l}\text { Odds } \\
\text { ratio }\end{array}$ & $\begin{array}{l}\text { Lower } \\
\text { limit }\end{array}$ & $\begin{array}{c}\text { Upper } \\
\text { limit }\end{array}$ & p-value & \\
\hline Group 8 & 0.85 & 0.73 & 0.98 & 0.03 & \\
\hline Group 9 & 0.88 & 0.82 & 0.93 & $<0.001$ & \\
\hline Overall & 0.87 & 0.82 & 0.92 & $<0.001$ & \\
\hline \multicolumn{5}{|c|}{ Note: Fixed effects model, $p=0.70$} & $\begin{array}{l}\mathbf{0 . 5} \\
\text { Favours intervention }\end{array}$ \\
\hline
\end{tabular}

Fig. 5. Effectiveness of criteria W (warn) on the smoking prevalence rate in adults during the longest follow-up period. 


\begin{tabular}{|c|c|c|c|c|c|}
\hline \multirow[b]{2}{*}{ Sub-area } & \multicolumn{4}{|c|}{ Statistics for each study } & \multirow[b]{2}{*}{ Odds ratio and $95 \% \mathrm{CI}$} \\
\hline & $\begin{array}{l}\text { Odds } \\
\text { ratio }\end{array}$ & $\begin{array}{c}\text { Lower } \\
\text { limit }\end{array}$ & $\begin{array}{c}\text { Upper } \\
\text { limit }\end{array}$ & p-value & \\
\hline Group 4 & 0.77 & 0.68 & 0.87 & $<0.001$ & \\
\hline Group 8 & 0.84 & 0.65 & 1.09 & 0.19 & \\
\hline Group 9 & 0.68 & 0.58 & 0.80 & $<0.001$ & \\
\hline Group 10 & 0.66 & 0.51 & 0.85 & $<0.001$ & \\
\hline Group 11 & 0.72 & 0.44 & 1.18 & 0.19 & $F$ \\
\hline Overall & 0.74 & 0.68 & 0.80 & $<0.001$ & \\
\hline Note: Fixed & ects $n$ & lel, p = & & & $\begin{array}{ll}\mathbf{0 . 5} & 1 \\
\text { Favours intervention } & \text { Favours c }\end{array}$ \\
\hline
\end{tabular}

Fig. 6. Effectiveness of criteria $P$ (protect), $W$ (warn) and $E$ (enforce) on the smoking prevalence rate in adolescents during the longest follow-up period.

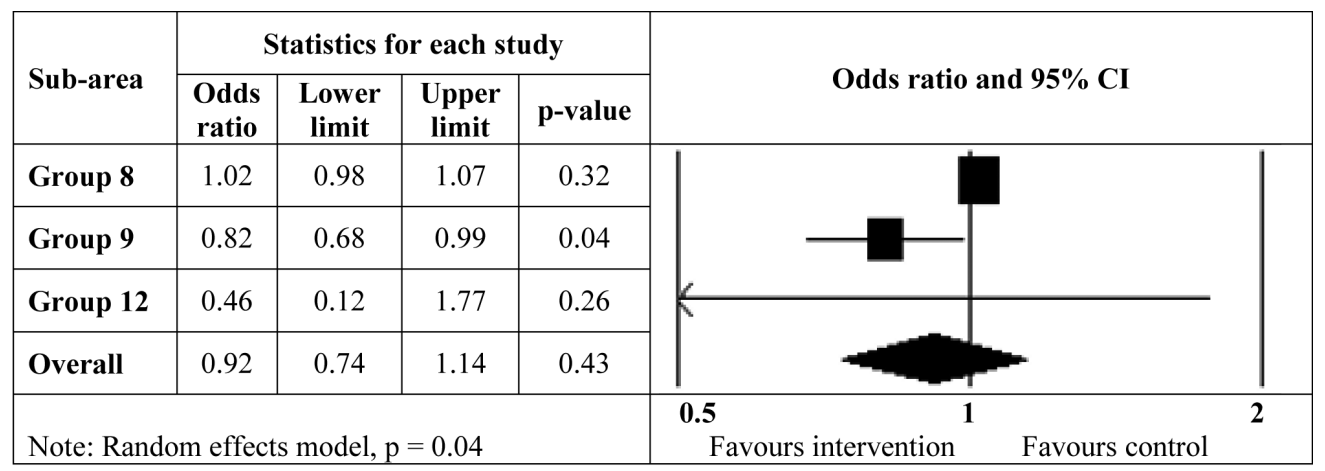

Fig. 7. Effectiveness of criteria $W$ (warn) and $R$ (raise) on the number of cigarettes smoked daily in adults during the longest follow-up period.

\section{DISCUSSION}

There are many meta-analysis and systematic review studies which evaluate the effectiveness of interventions and policies of MPOWER criteria on several outputs related to smoking in the literature (19-24). However, there is no study which evaluates the effectiveness of these interventions and policies in groups in sub-areas. Our study contributes to the literature by evaluating the effectiveness of the interventions individually and in groups.

In the current study, it is determined that $\mathrm{P}$ and $\mathrm{O}$ interventions, which are evaluated with smoking cessation rate, increased smoke cessation rate in adults in the longest follow-up period, whereas these interventions were not effective for smoking cessation rates in adolescents. According to these results, prohibition of smoking in outdoor environments such as hospitals and workplaces as well as providing professional health support to people increase the rate of smoking cessation.

It was reported that these interventions separately affect the smoking cessation rate in adults $(25,26)$. The interventions of professional health support activities that help to quit smoking in adults and the restrictions of smoking in settings such as hospitals, workplaces, and schools should be supported by all countries.
However, our study showed that professional health support does not seem to be effective for smoking cessation of adolescents. Adolescents may not be as willing to quit smoking as adults, due to the differences in age and biological conditions and their attitude not taking the interventions seriously. It is also mentioned in the study by Harvey and Chadi that the antismoking interventions should have different characteristics in adolescents (27).

In the current study, the only effective intervention on smoking cessation rate in adolescents was "studies on prevention of smoking in schools". Combining anti-smoking interventions for adolescents with interventions in schools can increase success of the fight against smoking.

The most effective sub-area intervention on smoking cessation rate in adults was "studies on nicotine replacement therapy." The usage of NRT is one of the effective methods used in smoking cessation studies in adult individuals. It is reported in the metaanalysis study of Wu et al. that NRT usage increased smoking cessation rate in adults by two times in 3-month period and by $75 \%$ in 12 -month period (18).

It is found that $\mathrm{W}$ and $\mathrm{R}$ interventions, which are evaluated with smoking prevalence rate, decreased smoking prevalence rate in adults and $\mathrm{P}, \mathrm{W}$ and $\mathrm{E}$ interventions decreased smoking prevalence rate in adolescents both in the longest follow-up period. 
The most effective intervention on smoking prevalence rate in adults was "studies on use of mandatory anti-smoking TV broadcasts and media campaigns." In the study by Méndez et al., the most effective MPOWER intervention on smoking cessation rate was reported as "studies on use of mandatory anti-smoking TV ads and media campaigns" (28).

Our study showed that adults are affected by the pictures and cautionary writings on cigarette packs and mandatory anti-smoking ads on TV in the long term. At this point, it is recommended that the anti-smoking ads and warnings on cigarette packs should be made mandatory in all countries in order to increase awareness of smoking cessation.

The importance of media campaigns that would create antismoking awareness especially for smokers was emphasized in order to prevent tobacco epidemic in a mathematical modelling study in Australia in 2014 (29).

It is observed that the warnings on cigarette packs are more effective in adolescents. For this reason, anti-smoking TV ads which are more effective in adolescents should be selected. In this way, it can be ensured that adolescents are more affected by anti-smoking ads. In the study of Unal et al., it was determined that adolescent individuals were particularly affected by the scary anti-smoking ads (30).

Besides, the prohibition of cigarette advertisements and sponsors affect the smoking frequency of adolescent individuals while limiting the age of purchase with 18 does not affect adolescents. Because there are laxities in the application of this law and inspections are not sufficient. Anti-smoking studies in schools, compulsory TV ads, package warnings, and restrictions on cigarette sales and advertisements are effective for the prevalence of smoking in adolescents when applied together.

The most effective intervention on smoking prevalence rate was "studies on prohibition of cigarette ads and sponsorships" in adolescents. It is mentioned that studies on the prohibition of cigarette ads have no or limited impact on smoking $(31,32)$. However, it is reported that cigarette advertisements are effective in attracting the attention of children and young people and are creating a positive perception (33). Therefore, practice of prohibiting cigarette advertising and sponsorship should be continued and expanded.

We determined that $\mathrm{W}$ and $\mathrm{R}$ interventions, which are evaluated with number of cigarettes smoked daily, were not effective for number of cigarettes smoked daily in adults in the longest follow-up period. The only effective intervention on the number of cigarettes daily smoked in adults was "studies on regulations locating stimulant writing and pictures on cigarette packs".

In the literature, it is stated that the most effective method regarding smoking cessation is increasing the taxes on tobacco products $(7,34)$. However, in our study the increase in cigarette taxes was not found to be effective for the number of cigarettes smoked daily. The practice of increasing taxes was also ineffective when combined with cigarette pack warning and anti-smoking ads. Our study has shown that although these interventions can be effective for smoking cessation, they do not cause people to reduce their daily smoking consumption. As a limitation, we could not find any study conducted on adolescents assessing the number of cigarettes smoked daily during the search phase of the study. Further studies are also needed on this output.

\section{CONCLUSIONS}

It was determined that MPOWER interventions were effective for the outputs which are related to smoking and the effectiveness varied in different age groups and different time periods. Although the effectiveness of these interventions is insufficient or low in countries and age groups, the anti-smoking interventions can be more effective in society when applied in combination.

From this point of view, it has been concluded that the interventions are needed to be continued by spreading to the wider segments of society. There is a necessity of further studies on ineffective areas that needs to be developed in order to make them effective. Cost-effective, well-planned and well-controlled antismoking interventions will be very critical to protect community from harm of smoking and economic losses.

\section{Funding}

This study was partly supported by the Research Fund of Eskisehir Osmangazi University (Project number: 201611A204).

\section{Conflict of Interests}

None declared

\section{REFERENCES}

1. World Health Organization. Tobacco fact sheet [Internet]. Geneva: WHO; 2015 [cited 2020 May 27]. Available from: http://www.who.int/ mediacentre/factsheets/fs339/en/.

2. Tobacco Control Studies in Turkey in 2012 [Internet]. Ankara: T.R. Ministry of Health; 2012 [cited 2017 Jan 29]. Available from: http://www. saglik.gov.tr/TR/belge/1-15787/turkiyede-tutun-kontrolu-calismalari. html. (In Turkish.)

3. Mathers CD, Loncar D. Projections of global mortality and burden of disease from 2002 to 2030. PLoS Med. 2006;3(11):e442. doi: 10.1371/ journal.pmed.0030442.

4. World Health Organization. Global status report on noncommunicable diseases 2014. Geneva: WHO; 2014.

5. T.R. Ministry of Health, Public Health Agency of Turkey. Global adult tobacco survey Turkey report 2012 [Internet]. Ankara: T.R. Ministry of Health; 2014 [cited 2017 Jan 26]. Available from: http://www.halksagligiens.hacettepe.edu.tr/KYTA TR.pdf. (In Turkish.)

6. World Health Organization. The Tobacco atlas. Geneva: WHO; 2002.

7. WHO report on the global tobacco epidemic, 2008: the MPOWER package. Geneva: WHO; 2008.

8. World Health Organization. MPOWER : a policy package to reverse the tobacco epidemic. Geneva: WHO; 2008.

9. WHO report on the global tobacco epidemic, 2013: enforcing bans on tobacco advertising, promotion and sponsorship. Geneva: WHO; 2013.

10. Kahende JW, Loomis BR, Adhikari B, Marshall L. A review of economic evaluations of tobacco control programs. Int J Environ Res Public Health. 2009;6(1):51-68.

11. Moher D, Liberati A, Tetzlaff J, Altman DG; The PRISMA Group. Preferred reporting items for systematic reviews and metaanalyses: The PRISMA Statement. PLoS Med. 2009;6(7):e1000097. doi: 10.1371/ journal.pmed.1000097.

12. Jadad AR, Moore RA, Carroll D, Jenkinson C, Reynolds DJ, Gavaghan DJ, et al. Assessing the quality of reports of randomized clinical trials: is blinding necessary? Control Clin Trials. 1996;17(1):1-12.

13. Valdivieso López E, Rey-Reñones C, Rodriguez-Blanco T, Ferre Grau C, Arija V, Barrera Uriarte ML, et al. Efficacy of a smoking prevention programme in Catalan secondary schools: a cluster-randomized controlled trial in Spain. Addiction. 2015 May;110(5):852-60.

14. Hamilton G, Cross D, Resnicow K, Hall M. A school-based harm minimization smoking intervention trial: outcome results. Addiction. 2005;100(5):689-700.

15. Isensee B, Hansen J, Maruska K, Hanewinkel R. Effects of a school-based prevention programme on smoking in early adolescence: a 6-month 
follow-up of the 'Eigenstandig werden' cluster randomised trial. BMJ Open. 2014 Jan 21;4(1):e004422. doi: 10.1136/bmjopen-2013-004422.

16. Gorini G, Carreras G, Bosi S, Tamelli M, Monti C, Storani S, et al. Effectiveness of a school-based multi-component smoking prevention intervention: The LdP cluster randomized controlled trial. Prevent Med. 2014;61:6-13.

17. Eisenberg MJ, Filion KB, Yavin D, Belisle P, Mottillo S, Joseph L, et al. Pharmacotherapies for smoking cessation: a meta-analysis of randomized controlled trials. CMAJ. 2008;179(2):135-44.

18. Wu P, Wilson K, Dimoulas P, Mills EJ. Effectiveness of smoking cessation therapies: a systematic review and meta-analysis. BMC Public Health. 2006 Dec 11;6:300. doi: 10.1186/1471-2458-6-300.

19. Hersi M, Traversy G, Thombs BD, Beck A, Skidmore B, Groulx S, et al. Effectiveness of stop smoking interventions among adults:protocol for an overview of systematic reviews and an updated systematic review. Syst Rev. 2019 Jan 19;8(1):28. doi: 10.1186/s13643-018-0928-x.

20. Carson KV, Ameer F, Sayehmiri K, Hnin K, van Agteren JE, Sayehmiri $\mathrm{F}$, et al. Mass media interventions for preventing smoking in young people. Cochrane Database Syst Rev. 2017 Jun 2;6(6):CD001006. doi: 10.1002/14651858.CD001006.pub3.

21. McNeill A, Gravely S, Hitchman SC, Bauld L, Hammond D, HartmannBoyce J. Tobacco packaging design for reducing tobacco use. Cochrane Database Syst Rev. 2017 Apr 27;4(4):CD011244. doi: 10.1002/14651858. CD011244.pub2.

22. Hartmann-Boyce J, Chepkin SC, Ye W, Bullen C, Lancaster T. Nicotine replacement therapy versus control for smoking cessation. Cochrane Database Syst Rev. 2018 May 31;5(5):CD000146. doi: 10.1002/14651858. CD000146.pub5.

23. Lindson N, Klemperer E, Hong B, Ordóñez-Mena JM, Aveyard P. Smoking reduction interventions for smoking cessation. Cochrane Database Syst Rev. 2019 Sep 30;9(9):CD013183. doi: 10.1002/14651858. CD013183.pub2.

24. Faber T, Kumar A, Mackenbach JP, Millett C, Basu S, Sheikh A, et al. Effect of tobacco control policies on perinatal and child health: a sys- tematic review and meta-analysis. The Lancet Public Health. 2017;2(9), e420-37. doi: 10.1016/S2468-2667(17)30144-5.

25. Cahill K, Lancaster T. Workplace interventions for smoking cessation. Cochrane Database Syst Rev. 2014 Feb 26;(2):CD003440. doi: 10.1002/14651858.CD003440.pub4.

26. Matkin W, Ordóñez-Mena JM, Hartmann-Boyce J. Telephone counselling for smoking cessation. Cochrane Database Syst Rev. 2019 May 2;5(5):CD002850. doi: 10.1002/14651858.CD002850.pub4.

27. Harvey J, Chadi N. Strategies to promote smoking cessation among adolescents. Paediatr Child Health. 2016 May;21(4):201-8.

28. Méndez D, Alshanqeety O, Warner KE. The potential impact of smoking control policies on future global smoking trends. Tob Control. 2013;22(1):46-51.

29. Goyal A. Tobacco epidemics: effect of marketing bans and awareness programs on its spread. Appl Math Comp. 2014;247:1030-51.

30. Unal E, Gokler ME, Metintas S, Kalyoncu C. Effect of anti-smoking advertisements on Turkish adolescents. East Mediterr Health J. 2016;22(9):654-61.

31. Saffer H. Tobacco advertising and promotion. In: Jha P, Chaloupka FJ, editors. Tobacco control policies in developing countries. Oxford: Oxford University Press; 2000. p. 215-36.

32. Chaloupka FJ, Warner KE. The Economics of smoking. Working paper, no. 7047. Cambridge: National Bureau of Economic Research; 1999.

33. US Department of Health and Human Services, Centers for Disease Control an Prevention. Reducing tobacco use: a report of the Surgeon General. Atlanta: CDC; 2000.

34. Jawad M, Lee JT, Glantz S, Millett C. Price elasticity of demand of noncigarette tobacco products: a systematic review and meta-analysis. Tob Control. 2018 Nov;27(6):689-95.

Received June 16, 2020 Accepted in revised form January 29, 2021 